\title{
Quartz luminescence response to a mixed alpha-beta field: Investigations on Romanian loess
}

\author{
Constantin, Daniela; Jain, Mayank; Murray, Andrew S.; Buylaert, Jan-Pieter; Timar-Gabor, Alida
}

Published in:

Radiation Measurements

Link to article, DOI:

10.1016/j.radmeas.2015.01.001

Publication date:

2015

Document Version

Peer reviewed version

Link back to DTU Orbit

\section{Citation (APA):}

Constantin, D., Jain, M., Murray, A. S., Buylaert, J-P., \& Timar-Gabor, A. (2015). Quartz luminescence response to a mixed alpha-beta field: Investigations on Romanian loess. Radiation Measurements, 81, 110-115. https://doi.org/10.1016/j.radmeas.2015.01.001

\section{General rights}

Copyright and moral rights for the publications made accessible in the public portal are retained by the authors and/or other copyright owners and it is a condition of accessing publications that users recognise and abide by the legal requirements associated with these rights.

- Users may download and print one copy of any publication from the public portal for the purpose of private study or research.

- You may not further distribute the material or use it for any profit-making activity or commercial gain

- You may freely distribute the URL identifying the publication in the public portal 


\title{
Quartz luminescence response to a mixed alpha-beta field: investigations on Romanian loess
}

\author{
D. Constantin ${ }^{1,2,3}$, M. Jain ${ }^{4}$, A.S. Murray ${ }^{5}$, J.P. Buylaert ${ }^{4,5}$, A. Timar-Gabor ${ }^{1,2 *}$ \\ ${ }^{1}$ Faculty of Environmental Sciences and Engineering, Babeş-Bolyai University, Cluj-Napoca, Romania \\ ${ }^{2}$ Interdisciplinary Research Institute on Bio-Nano-Science, Babeş-Bolyai University, Cluj-Napoca, Romania \\ ${ }^{3}$ Faculty of Biology and Geology, Babeş-Bolyai University, Cluj-Napoca, Romania \\ ${ }^{4}$ Center for Nuclear Technologies, Technical University of Denmark, DTU Ris $\phi$ campus, Roskilde, Denmark \\ ${ }^{5}$ Nordic Laboratory for Luminescence Dating, Department of Geoscience, Aarhus University, Ris $\phi$ campus, Roskilde, \\ Denmark \\ *Corresponding author: alida.timar@ubbcluj.ro
}

Abstract

Previous SAR-OSL dating studies using quartz extracted from Romanian and Serbian loess samples report SAR-OSL dose-response curves on fine grained $(4-11 \mu \mathrm{m})$ quartz that grow to much higher doses compared to those of coarse-grained $(63-90,90-125,125-180 \mu \mathrm{m})$ quartz. Furthermore, quartz SAR-OSL laboratory dose response curves do not reflect the growth of the OSL signal in nature. A main difference in coarse- and finegrained quartz dating lies in the alpha irradiation history, but the effect of mixed alpha-beta fields has so far received little attention. In the present study we investigate whether the alpha dose experienced by fine grains over geological cycles of irradiation and bleaching may have an effect on the saturation characteristics of the laboratory dose response. By applying time resolved optically stimulated luminescence we confirm that the OSL signals induced in quartz by alpha and beta radiation follow the same recombination path. We also show that a mixed alpha-beta dose response reproduces the beta dose response only up to about $800 \mathrm{~Gy}$. Assuming an a-value of 0.04 we have shown that laboratory alpha and beta dose response curves overlap up to effective alpha doses of $\sim 50 \mathrm{~Gy}$. Based on these results, we conclude that exposure of fine grains to alpha radiation during burial and transport cycles prior to deposition, as well exposure to the mixed radiation field experienced during burial are not responsible for the age discrepancies previously reported on fine and coarse grained quartz extracted from Romanian and Serbian loess.

Keywords: alpha radiation, beta radiation, quartz, OSL

\section{Introduction}

Heavy charged particles such as alpha particles (helium ions) deposit a large amount of energy per unit track length when interacting with matter and cause dense ionization and, in the case of luminescence dosimeters, local charge saturation effects in the vicinity of their tracks. Because of these saturation effects, the OSL output 
11 per unit dose from alpha particles is lower than that from high-energy electrons (beta irradiation) or photons

23 (gamma irradiation or X rays). This difference in OSL response is quantified by the alpha efficiency parameter 4

35 relative to beta irradiation (a-value). The lower luminescence response to alpha irradiation with respect to that $4 \begin{aligned} & 6 \\ & 7\end{aligned}$ of beta and gamma radiation in quartz, both in the case of TL and OSL has been known for a long time $5 \frac{8}{9}$ (Zimmerman, 1972; Aitken and Bowman, 1975). This effect becomes especially important in 'fine-grain' $6_{11}^{10}$ dating, because external alpha particles can irradiate the entire volume of the grain. Although, there has been an 712 increasing focus on dating fine grained quartz in the last decade (e.g.Lowick et al. (2010); Sugisaki et al. 13 (2010); Timar et al. (2010)) using the single aliquot regenerative dose protocol (Murray and Wintle, 2000), the subject of alpha efficiency has received little attention (Tribolo et al., 2001; Galloway, 2002; Burbidge et al., 2009; Polymeris et al., 2011). Reported estimates of alpha efficiency for fine grained quartz extracts is known to be around 0.1 in the case of thermoluminescence (Zimmerman (1972); Aitken (1985appendix K)), while in the case of OSL reported values vary between 0.03 and 0.04 (Rees-Jones, 1995; Mauz et al., 2006; Lai et al., 2008).

The range of alpha particles is $\sim 20 \mu \mathrm{m}$ in quartz (Aitken, 1985). Thus, they deposit energy in the entire volume of fine $(4-11 \mu \mathrm{m})$ grains, while only in an outer shell in coarse $(63-90 \mu \mathrm{m})$ grains. In the latter case the alphairradiated shell is etched away before measurement. The question we ask here is whether this difference in alpha affected volume can explain the differences in the OSL behaviour of the two size fractions from the loess in the Lower- as well as the Carpathian-Danube basin (Timar-Gabor et al., 2011; Timar-Gabor et al., 2012; Timar-Gabor and Wintle, 2013; Constantin et al., 2014a). These differences in OSL behaviour are observed in two ways: 1) on the one hand as observed in the Romanian loess, the laboratory dose response curves of fine quartz $\left(\mathrm{D}_{0}\right.$ of $\sim 175 \mathrm{~Gy}$ and $\sim 1800 \mathrm{~Gy}$ ) saturate much later than the etched coarse quartz $\left(\mathrm{D}_{0}\right.$ of $\sim 55 \mathrm{~Gy}$ and $\sim 600$ Gy), (see Timar-Gabor et al. (2012)); this behaviour has also been observed in other sites (e.g. Kreutzer et al. (2012); (Lomax et al., 2014; Timar-Gabor et al., 2014). 2) there is a general disagreement between fine and coarse quartz ages (Constantin et al., 2014a,b; Timar-Gabor et al., 2011; Timar-Gabor et al., 2012) which is likely to be due to the difference between the naturally and laboratory generated dose response curves (TimarGabor et al., 2011; Timar-Gabor et al., 2012; Timar-Gabor and Wintle, 2013; Constantin et al., 2014a; Constantin et al., 2014b). The divergence observed between the natural and the laboratory dose responses is observed for both grain fractions but is more pronounced in the case of fine grains (see Timar-Gabor and Wintle (2013), fig 6 and fig S1 a).

Assuming that the quartz has the same origin and physical characteristics irrespective of grain size, an important dosimetric difference between natural and laboratory irradiations lies in the dose rate and radiation field in the sediment matrix. The dose rate is $\sim 11$ orders of magnitude lower in nature compared to that in the laboratory. 
11 Similarly natural irradiations occur in a mixed radiation field (alpha, beta, gamma, x-rays) while laboratory 2

23 irradiations usually consist entirely of either beta particles or photons (gamma or X rays). These differences 4

35 may be reflected in calibration of luminescence response to dose and may arise from the different interaction

47 mechanisms of alphas and betas, and the possibility of additional defect creation due to alphas.

$5{ }_{9}^{8}$ In the present study we compare the dose response curves and sensitivity changes measured using continuous $6_{11}^{10}$ wave OSL (CW-OSL), under different combinations of alpha and beta irradiations designed to simulate the 712 effect of a natural radiation field. We use time-resolved optically stimulated luminescence (TR-OSL) as a tool 13 to gain insights into recombination pathways leading to the emissions generated by the two different types of radiations. These results are reported below.

1017

$11 \frac{19}{20}$

\section{Samples and measurement facilities}

Analyses have been performed on 4-11 $\mu \mathrm{m}$ and 63-90 $\mu \mathrm{m}$ quartz grains of sample CST 3 (Timar-Gabor and 1323

Wintle, 2013; Constantin et al., 2014a). Additional measurements have been carried out on $4-11 \mu \mathrm{m}$ quartz from sample LCA 26 (Constantin et al., 2014b). Relevant information on the samples is presented in Table S1. All investigations have been performed using large (9-mm diameter) aliquots that have been tested for purity by OSL IR depletion ratio (Duller, 2003; Wintle and Murray, 2006). The natural OSL signal was bleached by exposure to blue LEDs for $200 \mathrm{~s}$ at $20{ }^{\circ} \mathrm{C}$ prior to experiencing two cycles of regenerative beta dose of $350 \mathrm{~Gy}$ (preheat at $220{ }^{\circ} \mathrm{C}$ for $10 \mathrm{~s}$ ), test dose of $17 \mathrm{~Gy}$ (cutheat $180^{\circ} \mathrm{C}$ ) and elevated temperature bleach $\left(280{ }^{\circ} \mathrm{C}\right.$ for $\left.40 \mathrm{~s}\right)$. In the second cycle, an IR diode exposure for $100 \mathrm{~s}$ at $125^{\circ} \mathrm{C}$ preceded reading of the OSL signal induced by the regenerative dose.

Experiments have been carried out at DTU Nutech (DTU Ris $\emptyset$ Campus, Denmark) on a standard TL/OSL-DA20 reader (Thomsen et al., 2006) using an in-built ${ }^{90} \mathrm{Sr} /{ }^{90} \mathrm{Y}$ beta source (dose rate of 0.172 Gy s${ }^{-1}$ to $4-11 \mu \mathrm{m}$ grains deposited on aluminium disks and $0.219 \mathrm{~Gy} \mathrm{~s}^{-1}$ to $180-225 \mu \mathrm{m}$ quartz grains mounted on stainless steel disks) and an uncalibrated ${ }^{241}$ Am source under vacuum conditions. The OSL signal induced by 5000 s of alpha irradiation was found to be 2.22 times higher than that resulting from $\sim 8.5$ Gy of beta irradiation, giving an effective alpha dose rate of $0.095 \mathrm{~Gy} / \mathrm{s}$. This can be converted to a tentative absolute alpha dose rate of 2.370 Gy/s assuming an $a$-value of 0.04 for fine grained quartz (Rees-Jones, 1995).

All investigations into the optical emission characteristics of fine $(4-11 \mu \mathrm{m})$ and coarse $(63-90 \mu \mathrm{m})$ quartz used the SAR protocol (Murray and Wintle, 2003). The luminescence signals induced by alpha, beta and mixed alpha-beta radiation were stimulated with blue LEDs in continuous-wave $(\mathrm{CW})$ mode for $40 \mathrm{~s}$ at $125^{\circ} \mathrm{C}$ and the 55 3156 57 net CW-OSL signal was determined from the initial $0.32 \mathrm{~s}$ of the decay curve, less a background integrated between $1.76 \mathrm{~s}$ and $2.40 \mathrm{~s}$ (Ballarini et al., 2007; Cunningham and Wallinga, 2010). For the sake of consistency with previously reported data (Timar-Gabor et al., 2011; Timar-Gabor et al., 2012; Timar- 
11 Gabor and Wintle, 2013) a preheat at $220{ }^{\circ} \mathrm{C}$ for $10 \mathrm{~s}$ and a cutheat to $180{ }^{\circ} \mathrm{C}$ was used, together with

23 stimulation at $280{ }^{\circ} \mathrm{C}$ for $40 \mathrm{~s}$ at the end of each SAR cycle. Sensitivity changes induced by alpha and beta 4

35 irradiation were monitored using the response to a constant 17 Gy beta test dose.

$4 \underset{6}{7}$ Time-resolved optically stimulated luminescence (TR-OSL) was measured on a Ris $\varnothing$ TL/OSL-DA-20 reader $5 \begin{aligned} & 8 \\ & 9\end{aligned}$ equipped with an integrated pulsing option to control the stimulation LEDs and a photon timer attachment with $6_{11}^{10}$ a detection resolution (bin-width) of 100 ps (Lapp et al., 2009). TR-OSL experiments have been carried out 712 using the same parameters of the SAR protocol as in the CW-OSL measurements. The luminescence signals 13 were stimulated and recorded at $125^{\circ} \mathrm{C}$ for $100 \mathrm{~s}$ using pulsed optical stimulation (POSL). Each pulse consisted of an on-time (the duration of each LED stimulation pulse) of $50 \mu \mathrm{s}$ and an off-time time (the following period when the LEDs are not illuminated) of $450 \mu \mathrm{s}$. The photon counter was set to count photons during both on and off-time. The dose rates for beta irradiation on this particular reader were $0.099 \mathrm{~Gy} \mathrm{~s}^{-1}$ to $4-11 \mu \mathrm{m}$ quartz and $0.113 \mathrm{~Gy} \mathrm{~s}^{-1}$ to $180-225 \mu \mathrm{m}$ quartz.

\subsection{The effect of alpha irradiation history on the beta dose-response curve}

$17_{31}^{30}$ $18^{32}$ 33

One major difference when applying OSL dating to the fine and coarse quartz extracts is the fact that for the coarse fraction the outer alpha irradiated rim is etched away using HF. Thus, in the case of coarse quartz the material used for dating has not experienced alpha irradiation. Due to the different interaction mechanisms of alpha and beta particles with matter, the multiple cycles of irradiation and light exposure in the geological past of the fine grains and the fact that it is not proven without doubt whether alpha irradiation could cause defects involved in luminescence production we have aimed to investigate whether the higher saturation characteristics usually reported for fine grains compared to coarse grains (see e.g. Kreutzer et al. (2012); Timar-Gabor et al. (2012); Lomax et al. (2014)) could be at least partially, a consequence of past alpha history of the $4-11 \mu \mathrm{m}$ fraction. Three 63-90 $\mu \mathrm{m}$ quartz aliquots (sample CST 3) used in this experiment were first tested for IR depletion, followed by measurement of three consecutive SAR beta dose response curves up to $2.8 \mathrm{kGy}$ to check the reproducibility. Subsequently a total effective alpha dose of $9552 \mathrm{~Gy}$ (total alpha dose of $\sim 240 \mathrm{kGy}$ ) was delivered to the sample in 50 pulses of $182 \mathrm{~Gy}$, each pulse being followed by a bleach (exposure to blue LEDs for $200 \mathrm{~s}$ at $20^{\circ} \mathrm{C}$ ) in order to simulate natural irradiation and transport cycles as closely as possible. After these alpha irradiations, the SAR beta dose response was constructed, and compared to the first three growth curves. Finally, a fifth beta dose response was constructed to check the reproducibility. These five laboratory dose response curves are presented in figure 1. There is no significant variation between the pre- and the post- $\alpha$ irradiation dose response curves, and the saturation values for these curves agree with previously reported values for coarse quartz extracted from Romanian loess (Timar-Gabor et al., 2012). Assuming that 
11 OSL originates from the entire grain volume, the alpha skin contribution is expected to be less than $20 \%$ to the 2

23 total OSL (assuming a spherical grain of about $80 \mu \mathrm{m}$ diameter). But in practice the surface plays a far greater 35 role than the entire volume because of self-absorption of the photons emitted from the grains' core. Based on $4 \frac{6}{7}$ the results presented in figure 1 we therefore consider it unlikely that that prior alpha exposure plays a 58 significant role in affecting the shape of the subsequently measured beta dose response curves (see figure $\mathbf{S 1}$ a). $6^{10}$

\subsection{Luminescence lifetimes in quartz following alpha and beta irradiation}

Galloway (2002) suggested that the trapped electrons produced by alpha and beta irradiations use the same recombination pathways upon excitation with light. We have tested this by performing a time resolved 1017 experiment. One aliquot of CST 3 was first tested for purity using an IR depletion test. This aliquot was then bleached with blue LEDs for $200 \mathrm{~s}$ at $20{ }^{\circ} \mathrm{C}$ and irradiated for $120 \mathrm{ks}$ using the alpha source under vacuum conditions; this irradiation generates a luminescence response corresponding to that produced by a beta dose of

$455 \mathrm{~Gy}$. Assuming an a value of 0.04 , the expected total alpha dose is $\sim 11.4 \mathrm{kGy}$. The measurement conditions for the TR-OSL were chosen to be similar to those employed in CW-OSL: blue LEDs stimulation at $125^{\circ} \mathrm{C}$ and a $220{ }^{\circ} \mathrm{C}$ preheat for $10 \mathrm{~s}$, beta test dose of $19 \mathrm{~Gy}$, ramp heating to $180{ }^{\circ} \mathrm{C}$ (cutheat), elevated temperature OSL. 1628

The same measurement sequence was repeated using a beta regenerative dose of 581 Gy. The TR-OSL spectra recorded are presented in figure 2. The shapes of the photon-arrival time distributions are typical of quartz (Chithambo, 2003; Denby et al., 2006; Thomsen et al., 2008). The 54-500 $\mu$ s interval from the off time was fitted with an exponential function plus a constant (Figure 2 inset). Lifetimes of $35.3 \pm 0.2 \mu$ s and $35.6 \pm 0.2 \mu \mathrm{s}$ 2036 were calculated for the alpha and beta induced OSL signals $\left(\mathrm{R}^{2}=0.99\right)$. These results are also typical of quartz 37

(Chithambo, 2003; Ankjærgaard et al., 2010), and compare well with the previous findings of Galloway (2002) on the TR-OSL spectra of synthetic quartz.

\subsection{Mixed alpha beta dose response curves}

\subsubsection{Monitoring sensitivity changes following alpha irradiation using a beta test dose}

The SAR protocol is based on the assumption that sensitivity changes can be corrected by the response to a test dose. While laboratory irradiations are usually carried out using only beta or gamma irradiation, the following experiments are intended to examine the behaviour of our samples in mixed alpha/beta fields. Biswas et al. (2013) showed that a fixed $\beta$ test dose provides reliable normalization of the $\alpha$ and $\beta$ induced OSL signal growth in polymineral fine-grains extracted from volcanic ash samples, but Mauz et al. (2006) reported that for their fine-grained quartz the $\beta$ test dose did not provide a reliable correction for the sensitivity changes induced by $\alpha$ dosing. Because of this inconsistency, we have tested the basic assumption of the SAR protocol (Wintle and Murray, 2006) by examining the linearity between the regenerated (alpha dose) and the test (beta dose) 
11 response. The constant alpha regeneration dose amounted to an effective dose of 100 Gy, while beta test dose 2

23 was set to $17 \mathrm{~Gy}$.

4

35 Figure 3 shows the results for one aliquot of CST 3 and one aliquot of LCA 26. It can be seen that the

$4 \quad 7$ relationship is linear $\left(\mathrm{R}^{2}=0.98\right.$ and 0.94 , respectively) and the fitted functions pass close to the origin, indicating

58 that a beta test dose can satisfactorily monitor the factor of $\sim 2$ sensitivity changes induced by alpha irradiation. $6^{10}$

\subsubsection{Mixed alpha-beta dose response curves}

As the deviation between the laboratory and natural dose responses was reported to be more pronounced for the 4-11 $\mu \mathrm{m}$ quartz (see figure S1 b), we now investigate whether $\alpha$ and $\beta$ laboratory irradiations designed to 1017 reproduce as closely as possible the natural irradiation field produce a different growth curve compared to only $11_{20}^{19}$ beta irradiations.

1221 A mixed alpha-beta SAR dose response (normalized to a $17 \mathrm{~Gy}$ beta test dose) was build up to $800 \mathrm{~Gy}$ on one 1323 aliquot of fine quartz from sample CST 3, which was prior checked by an IR depletion test (Figure 4). The 24

1425 regenerative alpha doses represent effective alpha doses and were calculated based on the luminescence output 26 following $5 \mathrm{ks}$ of alpha irradiation and $50 \mathrm{~s}$ of beta irradiation and assuming an a-value of 0.04. Firstly a pure beta growth curve (dashed line) was constructed. For the combined $\alpha+\beta$ curve (solid line), the same 1730 regenerative dose levels were used. Each dose given comprised a $12 \%$ alpha share and an $88 \%$ beta share. In order to simulate as close as possible the natural conditions the alpha and beta doses were delivered alternatively, in alpha-beta pulses of an effective magnitude equivalent to 51 Gy of beta dose: $260 \mathrm{~s}$ beta (45 Gy) and 1523 s alpha (6 Gy of effective alpha dose, $\sim 150$ Gy of total alpha dose). A third beta dose response was constructed in order to check the reproducibility (dotted line). Finally, on the same aliquot a pure alpha 2239 2341 growth curve was constructed using the alpha doses given in the mixed dose points and a test dose of 17 Gy of beta (Figure 4 inset).

The mixed alpha-beta dose response curve and the beta dose-response growth curves are well fitted with a sum of two exponential functions; within the dose range investigated here they are indistinguishable (Figure 4). Up to 90 Gy (effective alpha dose) the alpha dose response is almost linear (inset Figure 4). The results indicate that over the investigated dose range the use of a constant a-value is justified and that the differences between

2850 2952 3054 55 3156 57 3258 3359 61 62

the natural and laboratory generated dose response curves for fine grains reported by Timar-Gabor and Wintle (2013) could not be accounted by an incorrect use for the value of the alpha efficiency.

\subsubsection{Extending the dose range of $\alpha$-generated OSL dose response curves}

Little work has been undertaken to determine the relative alpha to beta dose response (a-value) in quartz. Values such as 0.04 Rees-Jones (1995) or 0.03 (Mauz et al., 2006) are commonly adopted in quartz OSL dating 
11 studies. In the previous section we have shown that this is an appropriate decision in the case of our samples for 2

23 moderate doses. However, the contribution of the alpha dose to the total deposited energy in the quartz crystal 4

35 increases at higher doses, where less luminescence is created per unit beta dose. Saturation in the natural mixed

46 field implies a superposition of alpha and beta tracks. The interpretation of classic a-values at high dose is

58 complicated because the alpha and beta irradiations are performed separately. This may be relevant because $6_{11}^{10}$ Timar-Gabor et al. (2012) have reported natural OSL signals from an infinitely old quartz sample well below 11

Pure alpha growth curves were constructed on three aliquots of fine-grained quartz ( 2 aliquots of CST 3 and 1 aliquot of LCA 26) normalized to $17 \mathrm{~Gy}$ of beta irradiation. Dose points up to $1.6 \mathrm{kGy}$ of effective alpha $(\sim 40$ kGy of total alpha) were administered. For the sake of comparison, pure beta dose-response curves were constructed on each aliquot prior to alpha growth curve measurements, with beta dose points chosen to equal in light levels the given alpha doses. The growth of both alpha- and beta-induced OSL signal was fitted with a sum

of two saturating exponentials. Figure 5 shows the shapes of the alpha and beta dose-response growth curves. The inset in figure 5 plots the two beta dose responses as a function of the average alpha dose response (i.e. the 26 a-value). Note that the alpha and beta dose-response curves overlap up to 50 Gy of beta or alpha effective dose. This confirms that the $a$-value is constant over this dose-range. However, it appears that for dose $>300$ Gy the interpretation of the presented alpha dose-response is difficult since at high-doses either the a-value $18^{32}$ varies or the mechanisms responsible for luminescence production are different. Nevertheless, it is important to note that by considering an a-value of 0.04 (as used in our previous studies) (i) the alpha dose response does not saturate earlier than the beta dose response, (ii) for doses higher than $300 \mathrm{~Gy}$ the light output following alpha irradiation is higher for alpha than for beta doses of the same magnitude. This provides further evidence that the

$22 \begin{array}{r}39 \\ 40\end{array}$

$23 \frac{41}{42}$ 2443

44

2545

2647

278

$28 \frac{50}{51}$

2952

3054 55

3156

3258

3359 61

early saturation of the natural signals when compared to laboratory generated signals presented by Timar-

Gabor and Wintle (2013) cannot be accounted by the alpha dose received in nature by the fine grains.

\subsubsection{Can alpha irradiation overprint the effect of beta irradiation?}

Because of its high ionization power, alpha irradiation saturates any electron traps close to the alpha tracks. The presence of saturated alpha tracks in an area receiving a beta dose may affect the luminescence efficiency of this beta dose because in that area some traps cannot trap further charges. We test whether this model is of significance by building a mixed alpha beta growth curve for which a constant alpha irradiation (total alpha dose of $5000 \mathrm{~Gy}$ ) is administered prior to beta irradiation (Figure 6). For comparison pure beta growth curves have been constructed on the same aliquot before and after the mixed growth curve. Figure 6 shows that the pure beta dose-response curves as well as the mixed radiation dose response curves are reproducible and best fitted with a sum of two saturating exponentials. The characteristic doses are indicated for each dataset. These 


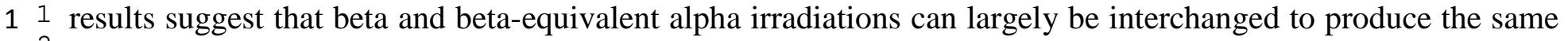
2

23 luminescence response, despite the fact that there is an order of magnitude difference in the dose rate and in the 4

35 ionization efficiency or LET (Linear Energy Transfer) between alpha and beta doses. Thus the two radiations

$4 \begin{aligned} & 6 \\ & 7\end{aligned}$ share the same traps, and there are no adverse, irreversible effects of saturation or defect creation during alpha

$5 \frac{8}{9}$ irradiation.

$6^{10}$

11

712

13

814

15

916

1017

\section{Summary and conclusion}

The presence of a prior alpha dose in etched 63-90 $\mu \mathrm{m}$ quartz grains does not alter the dose-response to laboratory beta irradiation as shown by the OSL growth curves constructed after irradiation with alpha doses of $9552 \mathrm{~Gy}$. It is thus not likely that the past natural alpha dose absorbed by the $4-11 \mu \mathrm{m}$ quartz grains is a cause for the growth of the OSL signal to much higher doses compared to coarse quartz, as has been previously reported for Romanian (e.g. Timar-Gabor et al. (2012)) and Serbian loess (Timar-Gabor et al., 2014). As reported by Galloway (2002), OSL signals induced by alpha irradiation and beta irradiation in fine grained 24

1425 quartz have similar luminescence lifetimes; an indication that the two emissions follow the same recombination 26 1527 path.

$16_{29}^{28}$ The differences regarding the shape and saturation characteristics of the OSL signal growth in nature and in $17_{31}^{30}$ laboratory reported for Romanian loess (Timar-Gabor and Wintle, 2013) are thought not to reside in the $18^{32}$ contribution of the alpha irradiation component in nature. We have shown that mixed alpha-beta dose response 33

2036 level matching and assuming an a-value of 0.04 we have shown that laboratory alpha and beta dose response 37

2138

2239

2341

2443

2545

46

\section{7}

2748

\section{Acknowledgements}

A.T-G. and D.C. acknowledge the financial support from a grant of the Romanian National Authority

2850

for Scientific Research CNCS-UEFISCDI, PN-II-RU-TE-2011-3-0062, nr. 73/05.10.2011. D.C. also 2952

3156 Environment and Earth".

$33 \frac{59}{6}$

\section{References}


23 Aitken, M., 1985. Thermoluminescence dating. Academic Press, London, p. 360.

4

35

46

58 $6^{10}$

Aitken, M.J., Bowman, S.G.E., 1975. Thermoluminescent dating: assessment of alpha particle contribution. Archaeometry 17, 6.

Ankjærgaard, C., Jain, M., Thomsen, K.J., Murray, A.S., 2010. Optimising the separation of quartz and feldspar optically stimulated luminescence using pulsed excitation. Radiation Measurements 45, 778-785.

Ballarini, M., Wallinga, J., Wintle, A.G., Bos, A.J.J., 2007. A modified SAR protocol for optical dating of individual grains from young quartz samples. Radiation Measurements 42, 360-369.

Biswas, R.H., Williams, M.A.J., Raj, R., Juyal, N., Singhvi, A.K., 2013. Methodological studies on luminescence dating of volcanic ashes. Quaternary Geochronology 17, 14-25.

Burbidge, C.I., Dias, M.I., Prudêncio, M.I., Rebêlo, L.P., Cardoso, G., Brito, P., 2009. Internal $\alpha$ activity: localisation, compositional associations and effects on OSL signals in quartz approaching $\beta$ saturation. Radiation Measurements 44, 494-500.

Chithambo, M.L., 2003. Dependence of the thermal influence on luminescence lifetimes from quartz on the duration of optical stimulation. Radiation Measurements 37, 167-175.

Constantin, D., Begy, R., Vasiliniuc, S., Panaiotu, C., Necula, C., Codrea, V., Timar-Gabor, A., 2014a. Highresolution OSL dating of the Costineşti section (Dobrogea, SE Romania) using fine and coarse quartz. Quaternary International 334-335, 20-29.

Constantin, D., Cameniţă, A., Panaiotu, C., Necula, C., Codrea, V., Timar-Gabor, A., 2014b. Fine and coarsequartz SAR-OSL dating of Last Glacial loess in Southern Romania. Quaternary International in press.

Cunningham, A.C., Wallinga, J., 2010. Selection of integration time intervals for quartz OSL decay curves. Quaternary Geochronology 5, 657-666.

Denby, P.M., Bøtter-Jensen, L., Murray, A.S., Thomsen, K.J., Moska, P., 2006. Application of pulsed OSL to the separation of the luminescence components from a mixed quartz/feldspar sample. Radiation Measurements 41, 774-779.

Duller, G.A.T., 2003. Distinguishing quartz and feldspar in single grain luminescence measurements. Radiation Measurements 37, 161-165.

Galloway, R.B., 2002. Comparison of luminescence lifetimes in quartz following alpha and beta irradiation. Radiation Measurements 35, 591-593.

Kreutzer, S., Fuchs, M., Meszner, S., Faust, D., 2012. OSL chronostratigraphy of a loess-palaeosol sequence in Saxony/Germany using quartz of different grain sizes. Quaternary Geochronology 10, 102-109.

Lai, Z.P., Zöller, L., Fuchs, M., Brückner, H., 2008. Alpha efficiency determination for OSL of quartz extracted from Chinese loess. Radiation Measurements 43, 767-770. 
11 Lapp, T., Jain, M., Ankjærgaard, C., Pirtzel, L., 2009. Development of pulsed stimulation and Photon Timer

2

23

4

35 Lomax, J., Fuchs, M., Preusser, F., Fiebig, M., 2014. Luminescence based loess chronostratigraphy of the

$4 \begin{aligned} & 6 \\ & 4\end{aligned}$

58

$6^{10}$

11

712

13

814

15

916

1017

$11^{19}$

121

22

1323

24

1425

26

1527

$16_{29}^{28}$

$17^{30}$

$18^{32}$

33

1934

35

2036

37

2138

2249

2341

2443

44

2545

46

2647

278

50

$28 \frac{50}{51}$

2952

53

3054

55

3156

57

3258

3359

61

62

63

64

65 Upper Palaeolithic site Krems-Wachtberg, Austria. Quaternary International 351, 88-97.

Lowick, S.E., Preusser, F., Pini, R., Ravazzi, C., 2010. Underestimation of fine grain quartz OSL dating towards the Eemian: Comparison with palynostratigraphy from Azzano Decimo, northeastern Italy. Quaternary Geochronology 5, 583-590.

Mauz, B., Packman, S., Lang, A., 2006. The alpha effectiveness in silt-sized quartz: new data obtained by single and multiple aliquot protocols. Ancient TL 24, 6 .

Murray, A.S., Wintle, A.G., 2000. Luminescence dating of quartz using an improved single-aliquot regenerative-dose protocol. Radiation Measurements 32, 57-73.

Murray, A.S., Wintle, A.G., 2003. The single aliquot regenerative dose protocol: potential for improvements in reliability. Radiation Measurements 37, 377-381.

Polymeris, G.S., Afouxenidis, D., Raptis, S., Liritzis, I., Tsirliganis, N.C., Kitis, G., 2011. Relative response of $\mathrm{TL}$ and component-resolved OSL to alpha and beta radiations in annealed sedimentary quartz. Radiation Measurements 46, 1055-1064.

Rees-Jones, J., 1995. Optical dating of young sediments using fine-grain quartz. Ancient TL 13, 9-14.

Sugisaki, S., Buylaert, J.-P., Murray, A., Tsukamoto, S., Nogi, Y., Miura, H., Sakai, S., Iijima, K., Sakamoto, T., 2010. High resolution OSL dating back to MIS 5e in the central Sea of Okhotsk. Quaternary Geochronology 5, 293-298.

Thomsen, K.J., Bøtter-Jensen, L., Denby, P.M., Moska, P., Murray, A.S., 2006. Developments in luminescence measurement techniques. Radiation Measurements 41, 768-773.

Thomsen, K.J., Bøtter-Jensen, L., Jain, M., Denby, P.M., Murray, A.S., 2008. Recent instrumental developments for trapped electron dosimetry. Radiation Measurements 43, 414-421.

Timar-Gabor, A., Constantin, D., Markovic, S., Jain, M., 2014. Extending the area of investigation of fine versus coarse quartz optical ages from the Lower Danube to the Carpathian Basin. Quaternary International in press.

Timar-Gabor, A., Vandenberghe, D.A.G., Vasiliniuc, S., Panaoitu, C.E., Panaiotu, C.G., Dimofte, D., Cosma, C., 2011. Optical dating of Romanian loess: A comparison between silt-sized and sand-sized quartz. Quaternary International 240, 62-70.

Timar-Gabor, A., Vasiliniuc, Ș., Vandenberghe, D.A.G., Cosma, C., Wintle, A.G., 2012. Investigations into the reliability of SAR-OSL equivalent doses obtained for quartz samples displaying dose response curves with more than one component. Radiation Measurements 47, 740-745. 
11 Timar-Gabor, A., Wintle, A.G., 2013. On natural and laboratory generated dose response curves for quartz of 2 different grain sizes from Romanian loess. Quaternary Geochronology 18, 34-40.

3 5 Timar, A., Vandenberghe, D., Panaiotu, E.C., Panaiotu, C.G., Necula, C., Cosma, C., van den haute, P., 2010. 46 Optical dating of Romanian loess using fine-grained quartz. Quaternary Geochronology 5, 143-148.

58 Tribolo, C., Mercier, N., Valladas, H., 2001. Alpha sensitivity determination in quartzite using OSL single $6 \quad$ aliquot procedure. Ancient TL 19, 4.

712 Wintle, A.G., Murray, A.S., 2006. A review of quartz optically stimulated luminescence characteristics and 13

916 Zimmerman, D.W., 1972. Relative thermoluminescence effects of alpha- and beta-radiation. Radiation Effects $10_{18}^{17} \quad 14,12$.

$11 \frac{19}{20}$

$12^{21}$

22

23

24

25

26

27

28

29

30

31 
3 Figure 1. The effect of irradiation with a total $\alpha$ dose of $238.8 \mathrm{kGy}$ (effective $\alpha$ dose of 9552 Gy assuming an $a$ value of 0.04 ) prior to the construction of the $\beta$ dose response curve. The dashed lines represent the $\beta$ dose response curves constructed on a single aliquot of 63-90 $\mu \mathrm{m}$ etched coarse quartz from sample CST 3 prior to alpha irradiation. The grey solid line represents $\beta$ dose response constructed on the same aliquot following $\alpha$ irradiation. $\alpha$ doses were delivered in pulses of $193 \mathrm{~Gy}$ followed by exposure to blue LEDs for $200 \mathrm{~s}$ at $20{ }^{\circ} \mathrm{C}$. The dose response was best described by a sum of two exponential functions and the characteristic doses are indicated for each growth curve.

Figure 2. Fine $(4-11 \mu \mathrm{m})$ quartz TR-OSL curves following alpha (grey solid line) and beta (black solid line) irradiation for sample CST 3. The TR-OSL spectra have been obtained by collecting signals during pulses (ontime of $50 \mu \mathrm{s}$ and off-time of $450 \mu \mathrm{s}$ ) that amount to a total time of $100 \mathrm{~s}$. Stimulation was carried out at $125^{\circ} \mathrm{C}$. The $\alpha$ irradiation time was $120 \mathrm{ks}$ which based on alpha and beta light levels matching for this aliquot and an a value of 0.04 corresponds to an effective dose of $455 \mathrm{~Gy}$. The given beta dose was $581 \mathrm{~Gy}$. Note that the luminescence intensities are similar. Inset: close-up showing TR-OSL spectra from the 54-100 $\mu$ s of the pulse. The solid lines indicate the best fit of the data: a single exponential decay plus a constant and the corresponding lifetimes. Please note the logarithmic scale.

Figure 3. Sensitivity changes over 10 cycles of alpha irradiation monitored using a 17 Gy $\beta$ test dose on one aliquot from sample CST 3 and one aliquot from sample LCA 26. In each cycle samples were exposed to a constant alpha irradiation time of $26260 \mathrm{~s}$, corresponding to an effective alpha dose of 100 Gy (considering an a-value of 0.04). A high degree of linearity can be noticed and the functions pass through the origin (intercept values are $-1720 \pm 1605$ (CST 3) and $768 \pm 2087$ (LCA 26)).

Figure 4. Mixed $\alpha-\beta$ dose response curve (solid line) normalized to a 17 Gy of beta. Each dose delivered combines a $12 \%$ contribution of alpha and $88 \%$ of $\beta$ irradiation, to reproduce the natural radiation field experienced by sample CST 3 (6 Gy eff $\alpha+45$ Gy $\beta, 12$ Gy eff $\alpha+90 \beta, 23$ Gy eff $\alpha+179 \beta, 47$ Gy eff $\alpha+$ $358 \beta, 93$ Gy eff $\alpha+717 \beta$ ). In order to better reproduce natural irradiation, doses have been delivered in mixed $\alpha / \beta$ pulses (6 Gy eff $\alpha+45$ Gy $\beta$ ). Pure beta growth curves were constructed before (dashed line) and after (dotted line) the mixed dose response one. The inset presents the pure alpha growth curve build on the same quartz aliquot using the alpha doses delivered in the mixed radiation experiment. Sensitivitity changes were monitored using a 17 Gy beta dose.

Figure 5. Comparison between beta (filled symbols) and alpha (open symbols) growth curves constructed on two aliquots of CST 3 (up-triangle and down-triangle) and one aliquot of sample LCA 26 (star). The alpha dose 
33 response was constructed on the same aliquot following the construction of the beta dose response. A constant 34 beta test dose of 17 Gy was used for correcting the sensitivity changes. The average beta dose response is 35 plotted against the average alpha dose response in the inset. Black solid line stands for 1:1 ratio and the dotted 36 lines bracket a 10\% deviation from it. Relevant regenerative doses (beta doses/effective alpha doses) are 37 indicated by arrows.

38 Figure 6. Mixed $\alpha+\beta$ dose-response curve (solid line) corrected using a 17 Gy $\beta$ test dose. Each mixed dose 39 point combines a fixed effective $\alpha$ irradiation equivalent of $200 \beta$ Gy (5000 Gy of total $\alpha$ ) prior to a $\beta$ dose. For 40 comparison, beta growth curves were constructed before (dashed line) and after (dotted line) the mixed one. 41 Recycling points are represented by stars. Saturation doses of the double exponential functions that best 42 described the data are indicated. 


\section{FIGURE 1}

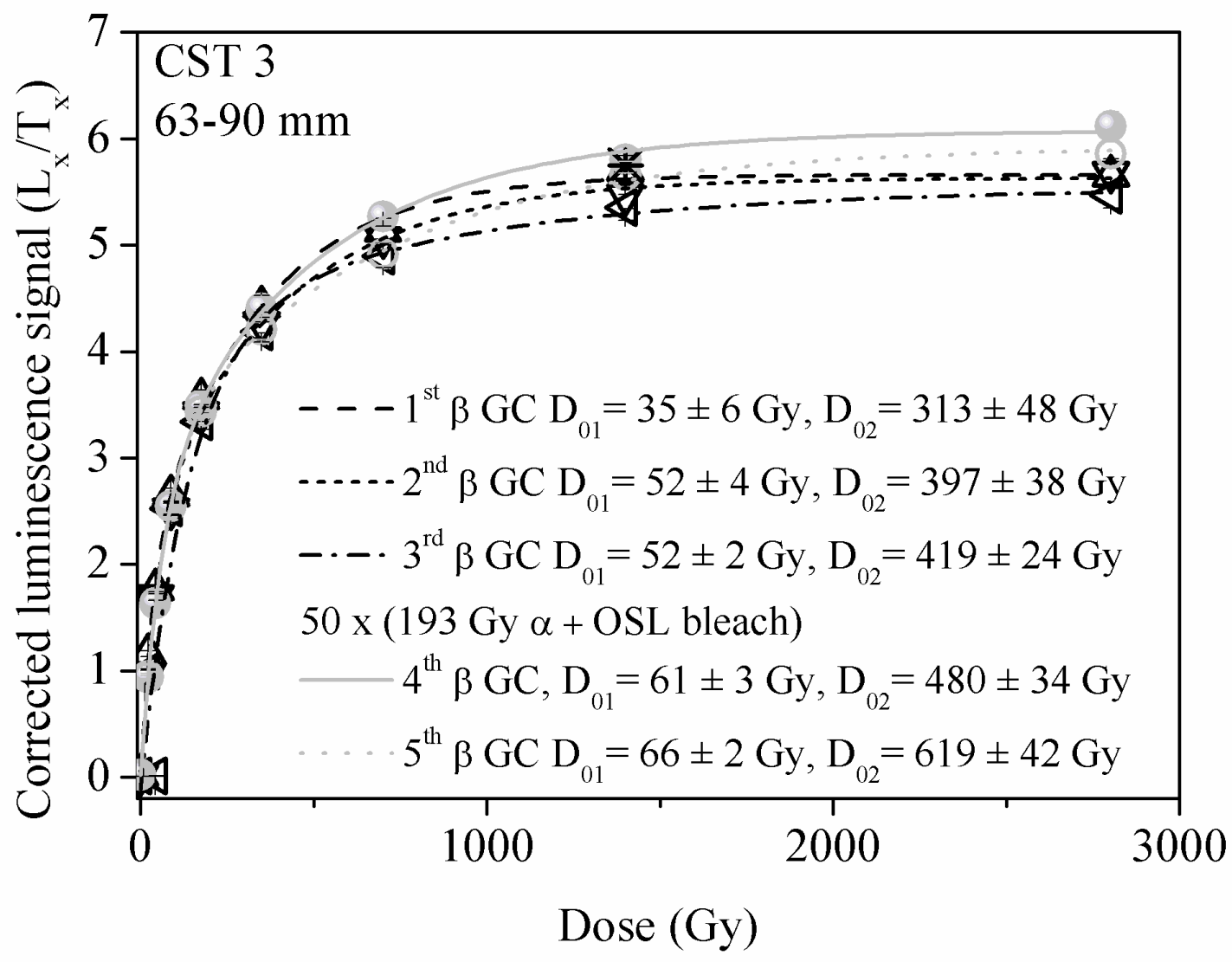


FIGURE 2

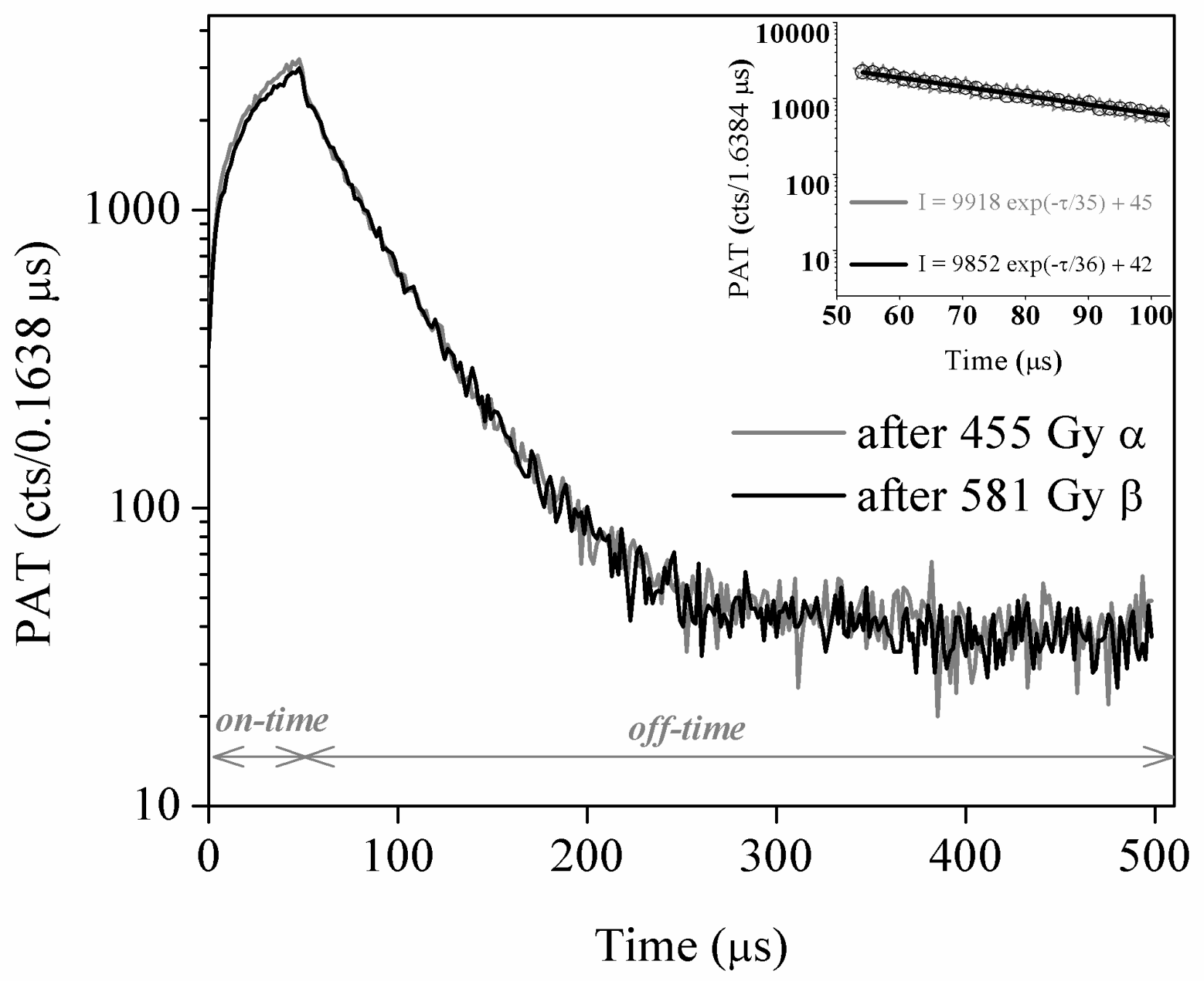




\section{FIGURE 3}

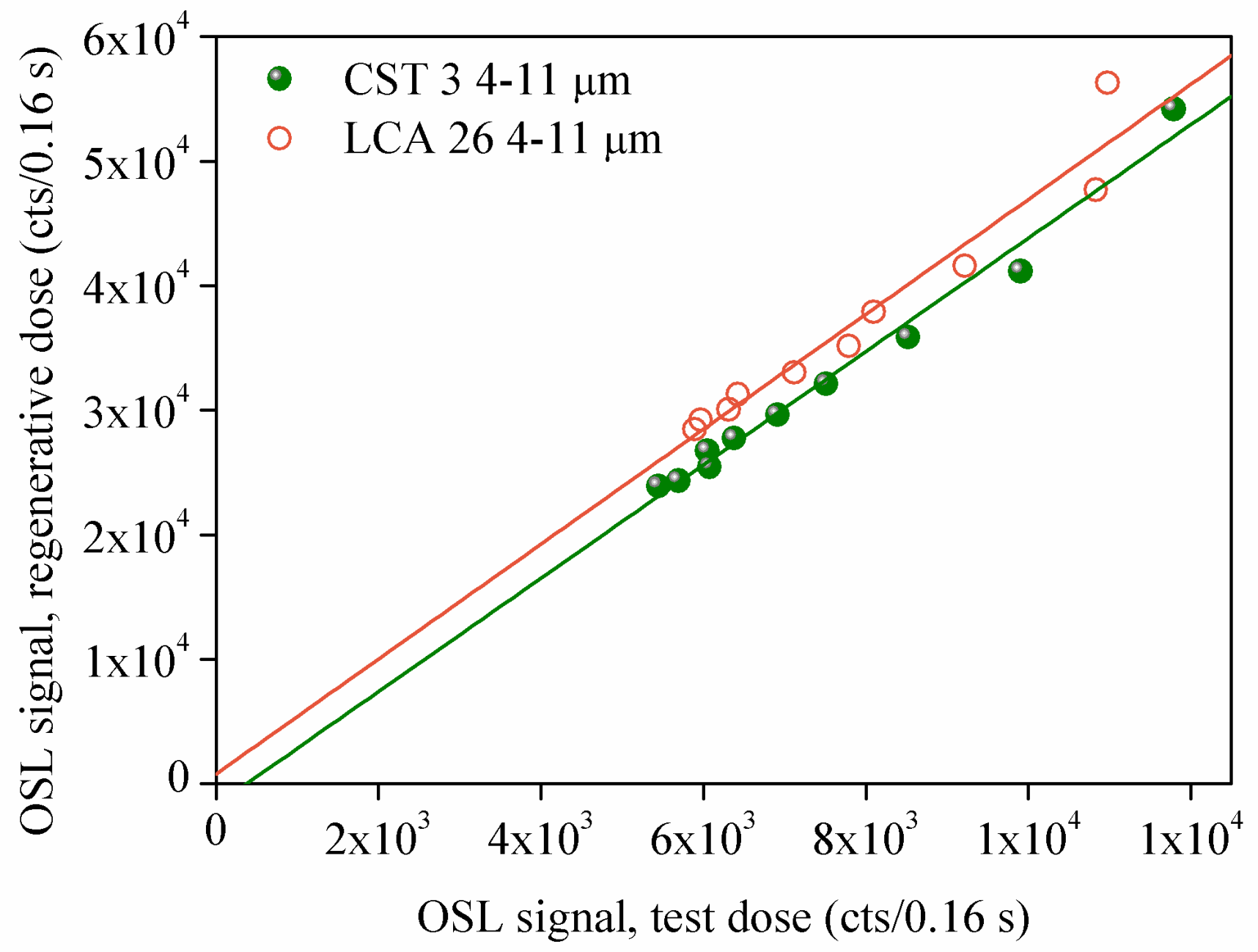


FIGURE 4

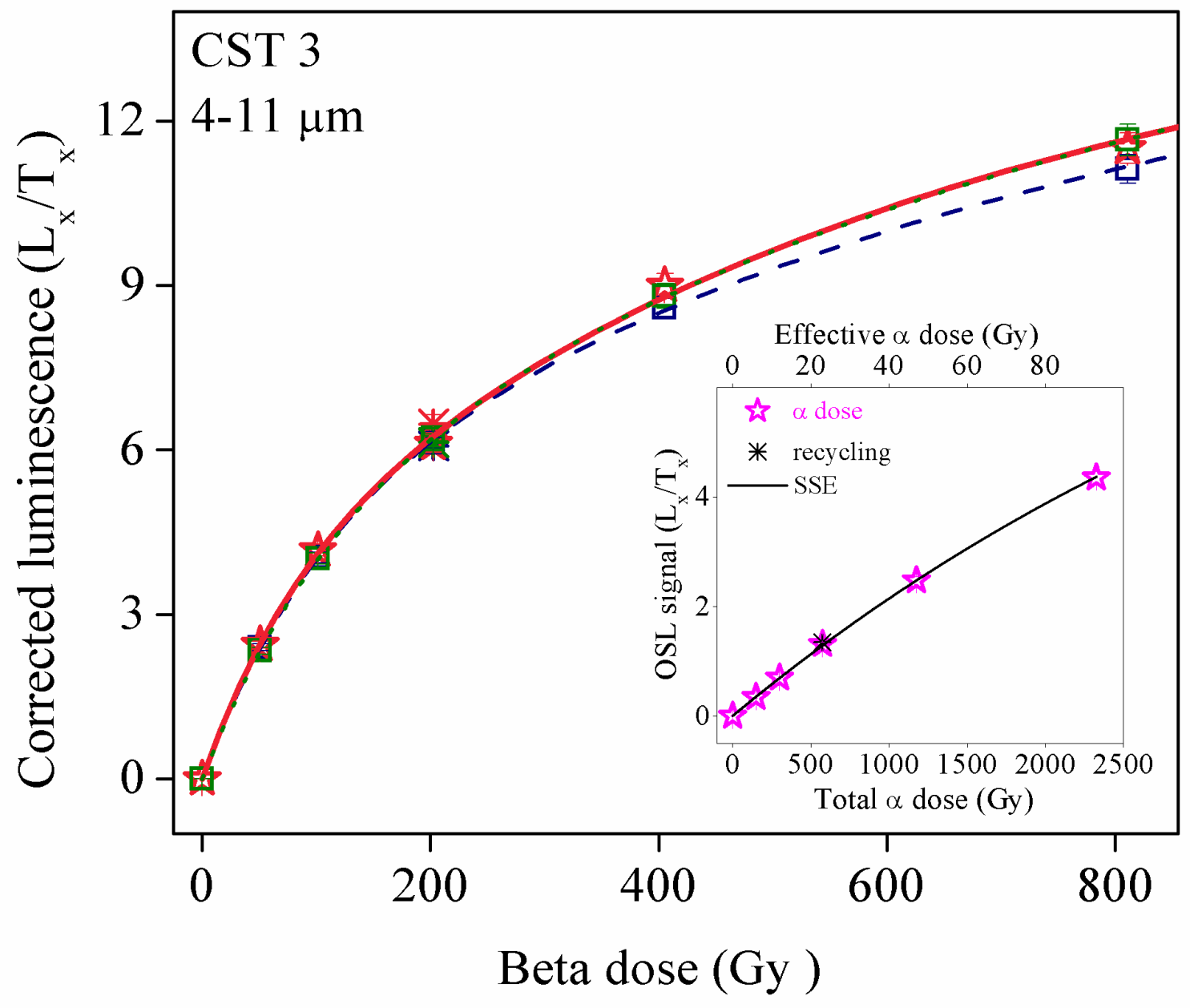




\section{FIGURE 5}

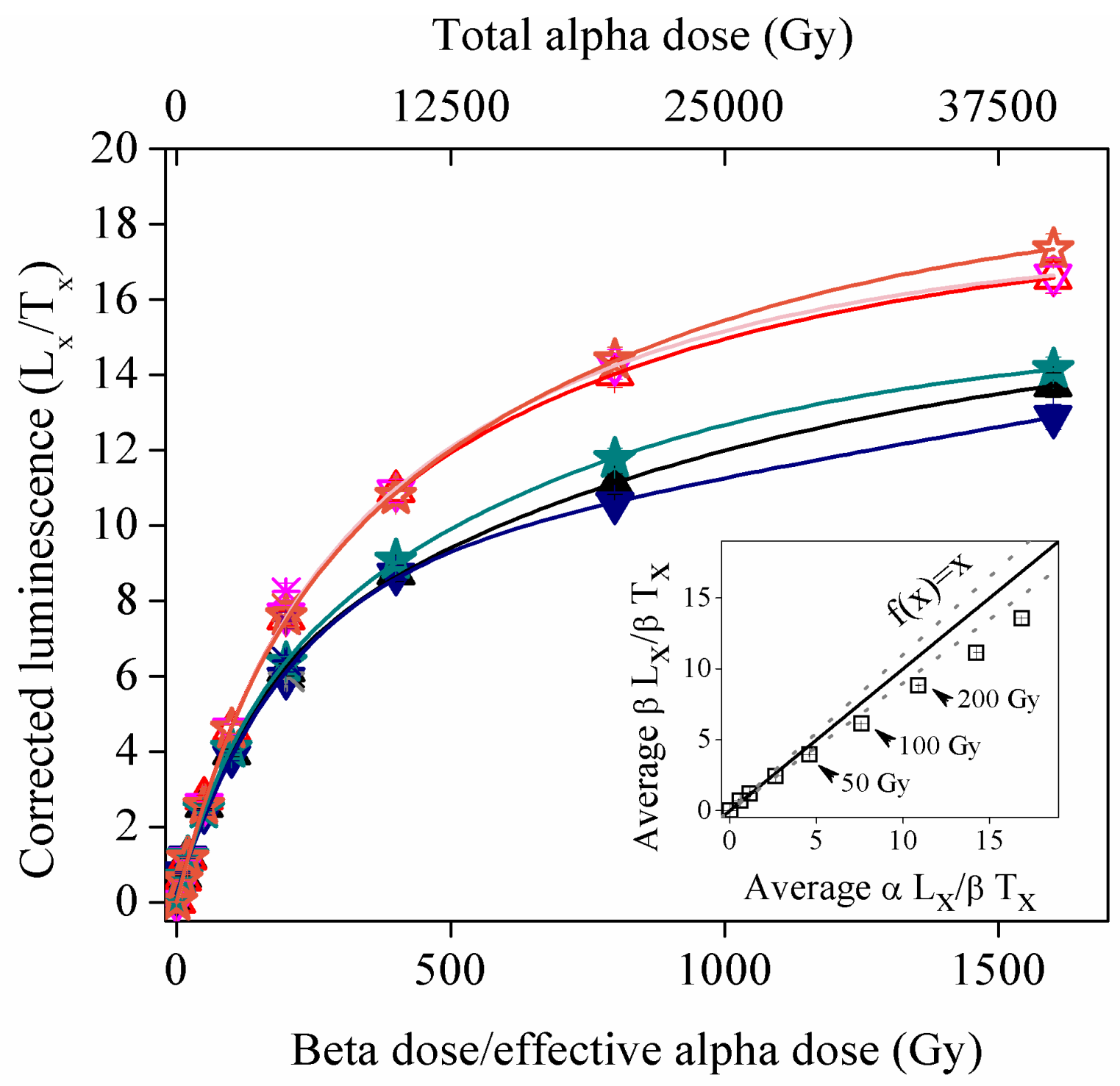




\section{FIGURE 6}

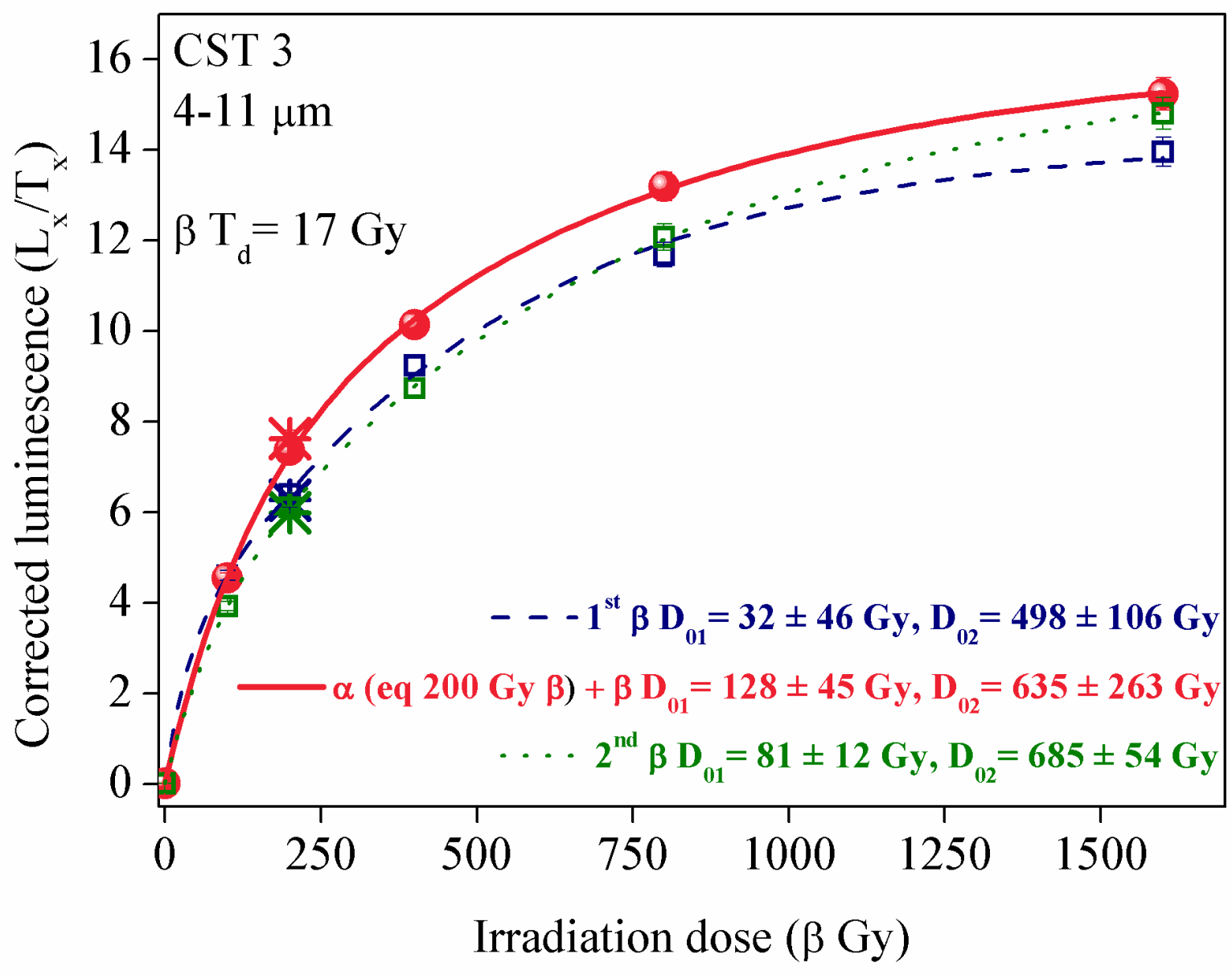




\section{SUPLEMENTARY MATERIAL}

Quartz luminescence response to a mixed alpha-beta field: investigations on Romanian loess D. Constantin, M. Jain, A.S. Murray, J.P. Buylaert, A. Timar-Gabor

Table S1. Information relevant for OSL dating on sample CST 3 (Constantin et al., 2014). A water content of $10 \pm 3 \%$ was assumed over geological times based on the measured water content of the sample when collected.

\begin{tabular}{|c|c|c|}
\hline Sample CST 3 & 4-11 $\mu \mathrm{m}$ & $63-90 \mu \mathrm{m}$ \\
\hline Equivalent dose (Gy) SAR protocol & $105 \pm 3$ & $117 \pm 6$ \\
\hline $\mathrm{U}-\mathrm{Ra}\left(\mathrm{Bq} \mathrm{kg}^{-1}\right)$ & \multicolumn{2}{|c|}{$31 \pm 2$} \\
\hline $\mathrm{Th}\left(\mathrm{Bq} \mathrm{kg}^{-1}\right)$ & \multicolumn{2}{|c|}{$33 \pm 1$} \\
\hline $\mathrm{K}\left(\mathrm{Bq} \mathrm{kg}^{-1}\right)$ & \multicolumn{2}{|c|}{$461 \pm 7$} \\
\hline Total annual dose rate $\left(\mathrm{Gy} \mathrm{ka}^{-1}\right)$ & $3.09 \pm 0.04$ & $2.62 \pm 0.03$ \\
\hline Alpha contribution to the total annual dose rate $\left(\mathrm{Gy} \mathrm{ka}^{-1}\right)$ corrected for water content & $0.36 \pm 0.07$ & \\
\hline Age (ka) & $34 \pm 3$ & $45 \pm 4$ \\
\hline
\end{tabular}




\section{SUPLEMENTARY MATERIAL}

Quartz luminescence response to a mixed alpha-beta field: investigations on Romanian loess

D. Constantin, M. Jain, A.S. Murray, J.P. Buylaert, A. Timar-Gabor
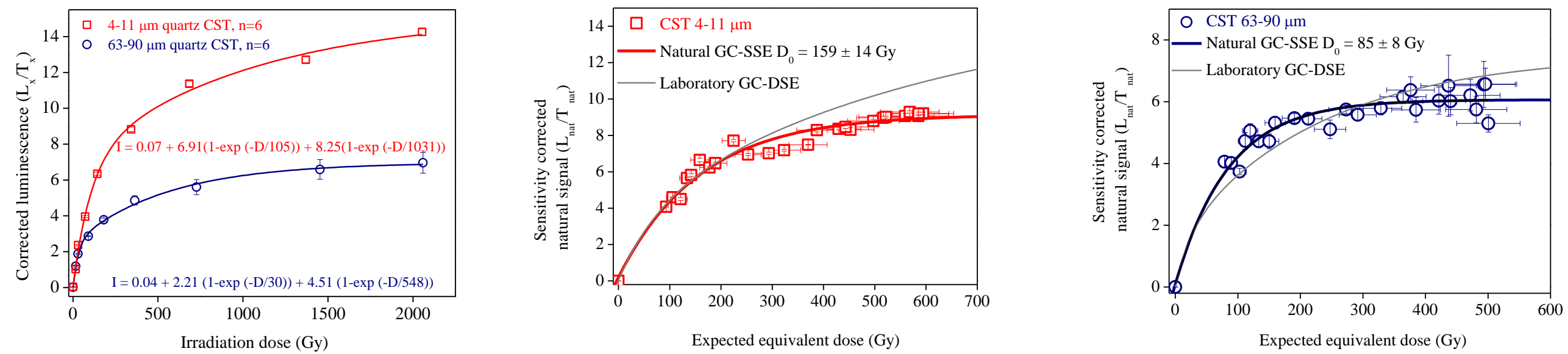

Figure S1. (a) Representative average sensitivity corrected SAR-OSL beta growth-curves for 4-11 $\mu \mathrm{m}$ (open squares) and $63-90 \mu \mathrm{m}$ (open circles) quartz

extracted from the Costineşti loess section in Romania. The data are best fitted with a sum of two saturating exponential functions and the characteristic doses are given under each curve. Average sensitivity corrected natural signals $\left(\mathrm{L}_{\mathrm{n}} / \mathrm{T}_{\mathrm{n}}\right)$ on all investigated aliquots of fine (b) and coarse quartz $(\mathbf{c})$ plotted as function of their expected equivalent dose, derived from magnetic susceptibility ages. Data are fitted using a single saturating exponential (SSE) function. The average laboratory dose response curve fitted with a double saturating exponential (DSE) function is presented for comparison (Timar- Gabor et al., 2012; Timar-

\section{Gabor and Wintle, 2013).}

